\title{
ASPECTOS DA EDUCAÇÃO INFORMAL NA COLÔNIA BLUMENAU: o caso da linguiça Blumenau
}

\author{
ASPECTOS DE LA EDUCACIÓN INFORMAL EN LA COLONIA BLUMENAU: el \\ caso del salchichón Blumenau
}

\section{ASPECTS OF INFORMAL EDUCATION IN BLUMENAU COLONY: the case of}

\author{
Blumenau sausage
}

\author{
Paola Beatriz May Rebollar ${ }^{1}$ \\ https://orcid.org/0000-0002-2402-6825
}

\begin{abstract}
Resumo
Este artigo dá continuidade a uma reflexão que vem sendo realizada sobre as construções realizadas pelos imigrantes em Santa Catarina no confronto entre os conhecimentos trazidos das regiões de origem e a realidade encontrada nas colônias. Focalizamos aqui o segmento representado pelas famílias de imigrantes alemães que vieram para a antiga colônia Blumenau a partir de 1850 e seus descendentes empregando como fonte de informação os documentos presentes nos arquivos públicos locais e os relatos orais dos descendentes permitindo, de um lado, apreender as visões e vivências cotidianas desse grupo, e, de outro, obter informações valiosas sobre um produto em especial cuja receita foi e ainda é ensinada de geração em geração: a linguiça Blumenau. Este produto característico desta colônia em especial apresenta uma importância cultural até os dias atuais, mas o processo de ensino e aprendizagem envolvido na sua produção ao longo de mais de um século esteve a cargo de processos de educação informais, primeiro no âmbito da família e, posteriormente, no mundo do trabalho. A história da educação nas colônias teuto-brasileiras consiste num capítulo que promove a diversidade e demonstra a complexidade dos processos educacionais catarinenses e brasileiros. Conhecer a complexidade que integra a educação formal e informal é fundamental ao profissional da educação para pensar tanto o fazer pedagógico quanto seu papel na sociedade.
\end{abstract}

Palavras-chave: Teuto-brasileiros. Aprendizagem. Linguiça Blumenau.

\section{Resumen}

Este artículo continúa una reflexión que se viene realizando desde hace muchos años sobre las construcciones realizadas por inmigrantes en Santa Catarina a partir del enfrentamiento entre el conocimiento traído de las regiones de origen y la realidad que se encuentra en las colonias. Nos

\footnotetext{
${ }^{1}$ Doutorado em Programa de Pós-Graduação em Engenharia Civil pela Universidade Federal de Santa Catarina, UFSC, Brasil. Professora do Centro Universitário Municipal de São José, USJ e Faculdade Cesusc. E-mail: paola.rebollar@gmail.com
}

\section{Como referenciar este artigo:}

REBOLLAR, P. B. M. Aspectos da educação informal na colônia Blumenau: o caso da linguiça Blumenau. Revista Pedagógica, v. 23, p. 1-18, 2021. 
centramos aquí en el segmento representado por las familias de inmigrantes alemanes que llegaron a la antigua colonia Blumenau a partir de 1850 y sus descendientes utilizando como documentos los documentos presentes en los archivos públicos locales y los informes orales de los descendientes, permitiendo, por un lado, para aprehender las visiones y vivencias cotidianas de este colectivo, $y$, por otro, para obtener información valiosa sobre un producto en particular cuya receta se enseñó y se sigue enseñando de generación en generación: la linguiça Blumenau. Este producto característico de esta colonia en particular tiene una importancia cultural hasta el día de hoy, pero el proceso de enseñanza y aprendizaje involucrado en su producción durante más de un siglo estuvo a cargo de los procesos de educación informal, primero dentro de la familia y, luego, en el mundo. de trabajo. La historia de la educación en las colonias germano-brasileñas consta de un capítulo que promueve la diversidad y demuestra la complejidad de los procesos educativos en Santa Catarina y Brasil. Conocer la complejidad que integra la educación formal e informal es fundamental para que los profesionales de la educación reflexionen tanto sobre la práctica pedagógica como sobre su papel en la sociedad.

Palabras clave: Germano-brasileños. Aprendizage. Salchicha Blumenau.

\begin{abstract}
This article continues a reflection that has been carried out for many years about the constructions carried out by immigrants in Santa Catarina from the confrontation between the knowledge brought from the regions of origin and the reality found in the colonies. We focus here on the segment represented by the families of German immigrants who came to the former Blumenau colony from 1850 and their descendants using as documents the documents present in the local public archives and the oral reports of the descendants, allowing, on the one hand, to apprehend the visions and everyday experiences of this group, and, on the other, to obtain valuable information about a particular product whose recipe was and still is taught from generation to generation: the linguiça Blumenau. This characteristic product of this colony in particular has a cultural importance until today, but the process of teaching and learning involved in its production over more than a century was in charge of informal education processes, first within the family and, later, in the world of work. The history of education in the German-Brazilian colonies consists of a chapter that promotes diversity and demonstrates the complexity of the Santa Catarina and Brazilian educational processes. Knowing the complexity that integrates formal and informal education is essential for education professionals to think about both pedagogical practice and their role in society.
\end{abstract}

Keywords: German-Brazilians. Learning. Blumenau sausage.

\title{
INTRODUÇÃO
}

Esta pesquisa histórica trata de um tema que foi alvo de processos de ensino e aprendizagem informais em Santa Catarina e tem relação com a construção da identidade étnica teuto-brasileira, em especial dos grupos que ocuparam o território da antiga colônia Blumenau. O tema central desta pesquisa diz respeito aos processos de ensino e aprendizagem que ocorreram informalmente por décadas no âmbito familiar relacionados a um elemento cultural, a gastronomia, importante no processo de negociação e 
construção identitária.

Cabe destacar que foi empregada uma diferenciação entre os conceitos de educação formal, não-formal ou informal, conforme o entendimento apontado por Silva e Costa (2013). Entende-se educação formal como aquela realizada nos espaços escolares, alvo de planejamentos e práticas didático-pedagógicas específicas. Já a educação nãoformal refere-se a processos educativos que se originam de preocupações relacionadas com a formação integral do indivíduo empregando conhecimentos e experiências que não são tratados diretamente nos processos formais. Por fim, a expressão educação informal foi utilizada nesta pesquisa para apontar aprendizagens que ocorrem sem organização ou planejamento prévio, no contexto da vida cotidiana como um processo permanente.

A história da relação entre os alimentos e os diferentes grupos sociais surge no início do século XX como um campo de estudos historiográficos, porém heterogêneo e vasto (MENESES; CARNEIRO, 1997). As pesquisas de Jean-Paul Aron aproximaram tais estudos do campo das mentalidades, enfatizando o comer e aqueles que comem (ARON, 1974). A contribuição destas pesquisas diz respeito ao reconhecimento do papel dos significados e das escolhas alimentares. No Brasil, a obra de Luís da Câmara Cascudo (1983), publicada inicialmente em 1967, apresenta uma síntese da história da alimentação no país incluindo as transformações alimentares promovidas pelos grupos étnicos. Meneses e Carneiro (1997) relatam a existência de estudos históricos sobre a alimentação para alguns estados do nordeste, São Paulo e Minas Gerais e Paraná.

O embasamento teórico-metodológico para o desenvolvimento da pesquisa foi a corrente historiográfica denominada História do Tempo Presente. Esta oferece ferramentas e técnicas que permitem a problematização, a pesquisa e a análise dos processos e eventos que ocorreram nos séculos XIX, XX e XXI. A principal questão que envolve as pesquisas históricas deste período é a profusão de informações, difundidas pelas mídias, propagadas pela oralidade e expressas através de imagens e da arte. Devido a sua contemporaneidade com o pesquisador, estas informações aparecem desordenadas e esvaziadas de sua temporalidade. A abordagem central desta pesquisa histórica foi entender como os agentes sociais dotaram de valor um determinado produto a ponto dos conhecimentos e habilidades relacionadas a este, se transformar em alvo de processos educacionais informais, inicialmente no âmbito familiar e depois empresarial. 
A História da Educação nas colônias teuto-brasileira, seja nos espaços escolares formais ou no âmbito informal da família e do trabalho, tem relação direta com os desafios, adaptações e rupturas sociais, culturais e econômicas pelos quais passaram os grupos de imigrantes e seus descendentes. Nas palavras de Silva e Montagnoli (2013, p. 60) "as relações sociais, que são temporalmente definidas pela produção material dos homens, dão forma aos processos educacionais".

O método de análise empregado consistiu em dois pontos principais: o tratamento específico dado às fontes de pesquisa e a elaboração das narrativas. Todas as fontes foram tratadas utilizando o método crítico para evitar interpretações lineares e ingênuas da complexidade que está envolvida nos fenômenos sociais. Cada fonte consultada é interpelada por questionamentos: Quem escreveu, disse ou escolheu? Por que razão? A quem interessam estas informações? É fundamental o entendimento que fonte alguma (escrita, oral, patrimonial) é neutra porque sempre traz consigo a visão de mundo, a opinião das pessoas, órgãos ou instituições aos quais se relaciona (BACELLAR, 2015). A escrita, a oralidade, os monumentos e bens patrimoniais carregam representações de mundo destacando o que se quer lembrar e esquecer intencionalmente.

Já a narrativa dos resultados da pesquisa histórica é elaborada por meio do encontro das diferentes fontes históricas existentes. A forma de narrar os eventos e processos respeita as particularidades das fontes, mas procura relacioná-las para fundamentar os fenômenos que levaram à distinção do produto por parte deste grupo social em particular.

As fontes de pesquisa para realização desta pesquisa foram orais e escritas, de domínio público e particulares, como entrevistas, fotografias, monumentos, museus, nomes de ruas, obras de arte, festas e tradições locais (NORA, 1993; BOM MEIHY, 2004; FERREIRA, 2018). Os documentos escritos se referem a registros formais de processos e eventos. Foram utilizadas as narrativas históricas de Santa Catarina escritas por Walter Fernando Piazza e Laura Machado Hubener (2003), bem como, aquela escrita por Leonir Dalla'Alba (2008). Também foram empregados os compêndios de textos de diferentes autores organizados por Antonio Morga (2003) e Ana Brancher (1999). Sobre a colônia Blumenau foram analisados os textos organizados por Gilberto Schmidt Gerlach e as diversas pesquisas publicadas por Giralda Seyferth (2017, 2011, 2003, 1990). Por fim, foi 
utilizado o material produzido por Nelson Pamplona (2007) intitulado Sabores da Colônia Blumenau. No que diz respeito à educação nas colônias teuto-brasileiras de Santa Catarina foram analisadas as pesquisas de João Klug (1997), José Marcelo Freitas de Luna (2000), Walter Koch (2003), Alessandra Helena Wiederkher (2014) e Ademir Valdir Santos (2015).

As fontes para as pesquisas históricas também podem ser registros de diferentes tipos localizados em arquivos públicos. Nesta categoria, foram consultadas as traduções de cartas e outros documentos pessoais e oficiais, disponibilizadas por seus proprietários e publicadas na Revista Blumenau em Cadernos, que reúne publicações sobre a região desde 1957, e em outros documentos editados pelo Arquivo Histórico e Fundação Cultural de Blumenau.

As fontes orais também foram importantes para esta pesquisa porque permitiram refletir sobre o passado utilizando as memórias dos sujeitos que o vivenciaram. Trabalhar com memórias implica compreender que estas são narrativas construídas com informações que não podem ser acessadas por outras fontes. As memórias também podem acrescentar elementos que não constam dos documentos oficiais (RICOEUR, 2007; FERREIRA 2018; PORTELLI, 2016), como ocorre no caso dos conteúdos e habilidades ensinados e aprendidos de maneira informal nas colônias teuto-brasileiras. No campo das memórias, as fontes orais foram selecionadas empregando como critério o envolvimento com a produção da linguiça Blumenau. Foram entrevistados os gestores dos frigoríficos atuais, Defumados Belchior, Deschamps Alimentos, Fricar, Frigozinnke, Friwandall, Defumados Gesser, Konell Alimentícios e Olho Embutidos e Defumados que fazem parte da ALBLU.

Após esta Introdução, o texto está organizado em três sessões. Na primeira, denominada Colonização Alemã na Colônia Blumenau, são apresentadas informações sobre o processo de estabelecimento e formação da estrutura colonial. A sessão seguinte, intitulada Educação na Colônia Blumenau, destaca o contexto de estabelecimento dos processos educacionais formais no local. Por fim, a sessão chamada Os Aprendizados Caseiros Informais apresenta os processos informais de ensino e aprendizagem relacionados à produção da linguiça Blumenau. $O$ texto se encerra com as considerações finais nas quais são retomados os principais temas discutidos em relação à educação informal na colônia Blumenau e sua importância para a continuidade da produção da 
lingüiça Blumenau.

\section{COLONIZAÇÃO ALEMÃ NA COLÔNIA BLUMENAU}

A imigração para o Brasil durante a segunda metade do século XIX foi idealizada pelo governo brasileiro a fim de povoar terras devolutas. O regime de colonização escolhido foi a pequena propriedade. As colônias foram implantadas por iniciativa do próprio governo, em alguns casos, ou ainda por iniciativa privada.

Os primeiros estrangeiros que se instalaram no Vale do Itajaí foram alemães provenientes da colônia São Pedro de Alcântara na região central do litoral catarinense em 1836 (DALL'ALBA, 2008). Estas poucas famílias, porém, não constituíram um núcleo colonial. A colonização efetiva do vale teve início em 1850 no contexto das grandes migrações europeias. A empreitada colonizadora teve início com a iniciativa particular empreendida por Hermann Blumenau e seu sócio Ferdinand Hackradt que fizeram o requerimento de terras devolutas e adquiriram pequenas propriedades no médio vale para fundar a colônia Blumenau.

A escolha do local para instalação da sede da colônia aconteceu em uma expedição que partiu de Itajaí em duas canoas. Passaram pelo afluente Luiz Alves, pelo Morro do Baú, pela colônia Belga (atual Ilhota), pela colônia do Pocinho até chegar ao Belchior (Gaspar). Ao longo do caminho encontraram algumas clareiras e colonos esparsos. Seguiram navegando até chegar à embocadura dos Ribeirões da Velha e Garcia. Exploraram o rio do Testo, as regiões de Itoupava, da Fortaleza, bem como o curso do próprio Rio Itajaí até onde se encontra Indaial e os Rios Benedito e dos Cedros (GERLACH, 2019).

Hackradt e Blumenau concordaram em estabelecer a sede da colônia na confluência dos Ribeirões da Velha e Garcia para aproveitar o curso navegável do Rio Itajaí garantindo uma boa comunicação com o litoral. O primeiro ficou encarregado dos trabalhos preliminares na floresta para receber os imigrantes. O segundo ficou responsável pelas negociações com as autoridades brasileiras e com a propaganda e engajamento na Alemanha (GERLACH, 2019).

No ano de 1850 , chegaram dezessete colonos. Viajaram em um veleiro que atracou em Desterro (Florianópolis) e depois em outra embarcação até a foz do Itajaí e rio acima 
até Belchior (GERLACH, 2019; PIAZZA; HUBENER, 2003). Neste local, utilizaram uma balsa para se deslocar até o local escolhido para o estabelecimento da sede, entre os Ribeirões da Velha e Garcia, no local conhecido na época como Stadtplatz.

Na carta escrita pelo alemão Ferdinand Ostermann em 1853 é possível observar como foi a instalação dos colonos:

\begin{abstract}
ao receber seu lote ou que lhe fora destinado, iniciavam o desmatamento e construímos rústicas cabanas de bambu ou de árvores derrubadas. Recolhiam-se ao galpão que lhe fora destinado até o término da construção de suas casas. Esta permanência no rancho dos imigrantes era a faze mais dolorosa. $\mathrm{E}$ a comida estranha, de feijão, arroz e carne seca diariamente, e uma vez ou outra um pedaço de pão de milho. $O$ desespero era grande. Muitas lágrimas amargas foram derramadas; surgiam as doenças, crianças morriam, um ambiente triste e desolador. Uma vez terminadas as choupanas e instalados nelas recebiam o assim chamado "Budegeld" (dinheiro em casa). Eram 50 ou 100 mil réis como empréstimo para a continuação do trabalho e era adicionado ao preço total da compra que variava de 200 a 300 contos de réis e tinham 15 anos para pagar a dívida. Naturalmente, as pessoas não podiam sobreviver com este dinheiro até a primeira colheita. Quem podia, ainda trabalhava na abertura de estradas ou emprestava simplesmente no armazém. Assim passava o primeiro ano de necessidade, galinhas e porcos, quem podia os adquiria em pouco tempo, mas todos estavam empenhados em comprar o mais rápido possível uma vaca, que Ihes fornecesse leite, manteiga, queijo e auxiliava no sustento da família (OSTERMANN, 1862, p.71).
\end{abstract}

Nos anos seguintes, duzentos e quarenta e seis pessoas viviam na sede da colônia que já contava com dois engenhos de açúcar, dois alambiques e duas atafonas (GERLACH, 2019).

Diferentes núcleos coloniais foram estabelecidos ao longo dos principais rios e ribeirões da região. Alguns imigrantes foram encaminhados para o núcleo Belchior às margens do Rio Itajaí. Em 1861, um novo grupo de imigrantes alemães foi estabelecido ao longo do Rio Testo, formando o núcleo com o mesmo nome, como estratégia para criar um caminho terrestre e assim ampliar o comércio entre a colônia Blumenau e a colônia Dona Francisca, atual município de Joinville. As margens do Rio Benedito foram ocupadas em 1863 por imigrantes alemães dando origem ao núcleo Benedito. Em 1868, novos grupos de imigrantes alemães foram instalados na confluência dos Rios Benedito e dos Cedros dando origem ao núcleo Benedito Timbó. Em 1892, as margens do Suerdam (Braço do Sul ou Rio do Sul) foram ocupadas por imigrantes, formando o núcleo Bella Alliança (IBGE, 2020).

A colônia Blumenau e seus demais núcleos foram implantados em áreas de floresta 
com pouca ou nenhuma comunicação terrestre. Apesar das conexões através dos rios, os colonos passaram décadas sem muito convívio com a sociedade nacional. A colônia tornouse uma pátria, um lar (Heimat) no meio da floresta tropical.

\title{
2 EDUCAÇÃO NA COLÔNIA BLUMENAU
}

A educação era considerada pelos colonos como uma atividade importante (SEYFERTH, 2003). Poucos anos depois da instalação da colônia Blumenau foi contratado o primeiro professor, Ferdinand Ostermann. Wiederkeher (2014) destaca que nas primeiras décadas após a instalação da colônia, o número de escolas particulares era superior às escolas públicas.

A educação escolar local era organizada pelo professor e pelas comunidades escolares (Schulgemeinden) e compreendia entre três e seis anos de escolarização. $\mathrm{O}$ currículo enfatizava o que era "necessário" do ponto de vista dos atores: aprender a ler e escrever, bem como noções de matemática e geometria. O Relatório Sobre as Escolas Tirolesas (1987, p.53-54) no Município de Blumenau no ano de 1910 ainda apresenta esta estrutura do currículo da educação formal:

\begin{abstract}
A escola na sede da Paróquia Rodeio tem três classes e abrange cinco divisões. [...]. Aritmética: $01^{\circ}$ ano aprende a numeração de 1 a 20. $02^{\circ}$ ano abrange a numeração de 1 a 100 e as 4 operações com números bases e também com 2 números. No $1^{\circ}$ semestre na terceira classe, amplia-se a numeração até 1000 e no $2^{\circ}$ semestre até o número 1.000.000, para então parar, e na escrita dos números e das 4 operações. $04^{\circ}$ ano continua com estes exercícios, cálculos com dois ou mais números. No $5^{\circ}$ ano, inicia-se os cálculos necessários em escritórios com o respectivo cálculo de porcentagem. Geometria: a geometria começa no $2^{\circ}$ semestre do $4^{\circ}$ ano escolar e se ocupa com áreas e figuras geométricas e na maioria dos casos referente à vida do campo. (Relatório Sobre as Escolas Tirolesas, 1987, p.53-54).
\end{abstract}

Mas, as escolas nas colônias teuto-brasileiras do sul do Brasil tiveram um papel que foi além dos conteúdos colaborando com a construção de uma identidade local. Este papel vem sendo destacado por diferentes pesquisadores como Seyferth (1990) e Santos (2015). A construção de uma identidade ocorre em decorrência das relações entre diferentes grupos. Os contatos entre brasileiros e os imigrantes e seus descendentes promoveram mudanças e adaptações nas identidades trazidas da Europa e possibilitaram a construção 
da identidade local. As práticas curriculares educativas e formativas introduziram e difundiram também elementos identitários que foram construindo a germanidade nas colônias: "os processos de constituição cultural de porções meridionais do Brasil revelam a mistura de momentos de satisfação de sonhos e conquistas àqueles de dificuldades, conflitos e ambiguidades" (SANTOS, 2015, p.338).

Seyferth (2017) destaca que a construção da identidade teuto-brasileira foi objeto de fortes críticas das correntes nacionalistas que não aceitavam a diferença cultural nem a pluralidade étnica derivada da imigração. Esta crítica tornou-se ainda mais intensa depois do advento da República, em 1889. Neste contexto, o papel das escolas "alemãs" foi discutido pelos órgãos oficiais. De Martini (2010) destaca esta perspectiva sobre o papel da educação formal dos imigrantes para o Estado de São Paulo:

Os (imigrantes) que se aboletam nas cidades, facilmente se matriculam nas escolas diurnas, quando menores, e nas noturnas, quando adultos, aprendendo, numas e noutras, a falar a nossa língua e recebendo noções elementares de arithmética, geographia e história pátria; os que se estabelecem nos campos e nas fazendas, distantes dos centros urbanos, vivem crescem e prosperam na completa ignorância da língua, do meio, dos usos e costumes, dos nossos recursos, inteiramente estranhos à vida social e política do país que lhes dá hospitaleiro agasalho e fartura (ANNUÁRIO DO ENSINO, 1918, p. 129-131).

Os debates sobre o papel das escolas nas colônias teuto-brasileiras perduraram até 1937 quando foram nacionalizadas em um movimento que buscou a assimilação ampla dos imigrantes e descendentes. Até este evento, as escolas alemãs e as teuto-brasileiras foram palco de diversos embates ao longo da sua história. Nestes, surgiram tanto elementos positivos, quanto angústias e traumas. Neste sentido, a própria história da educação nas colônias teuto-brasileiras se torna um elemento de pertencimento e alteridade constituindo uma herança cultural compartilhada (SANTOS, 2015).

As escolas tiveram um papel importante nas colônias teuto-brasileiras tanto do ponto de vista da educação formal quanto da construção da identidade étnica do grupo. Apesar disso, diversos aspectos importantes tanto para a adaptação à realidade da colônia quanto para construção da identidade do grupo não foram ensinados e aprendidos nas escolas e ficaram a cargo de processos educacionais informais. É possível destacar diferentes exemplos incluindo alguns elementos cuja importância foi e ainda é tão grande a ponto de tornarem-se patrimônios culturais: as festas, as canções, as brincadeiras, a 
gastronomia, na qual se insere a linguiça Blumenau. Conforme apontado por Pelegrini (2008), o patrimônio cultural, reconhecido pela sociedade, reflete o sentimento de pertencimento a um grupo étnico e faz parte da sua dinâmica sócio-cultural. A gastronomia faz parte do conjunto "tradições populares" que possuem especificidades diferenciadoras, como "a degustação de inusitados sabores resultantes de maneiras singulares de cozinhar" (PELEGRINI, 2008, p. 150).

\section{OS APRENDIZADOS CASEIROS INFORMAIS}

O protagonismo dos colonos na implantação da educação formal é inegável e vem sendo estudado por diferentes pesquisadores (KLUG, 1997; LUNA, 2000; SEYFERTH, 2003; KOCH, 2003; WIEDERKHER, 2014; SANTOS, 2015). No entanto, diversos elementos culturais importantes ficaram à margem do sistema educacional oficial e seu ensino e aprendizagem foram desenvolvidos empregando práticas educativas informais.

Um exemplo disso diz respeito aos conhecimentos relacionados à produção de alimentos. Wolff (2003) destaca que os conhecimentos e habilidades de padeiro, cervejeiro, açougueiro, cozinheiro foram aprendidas nos ambientes domésticos e não escolares. A mesma autora apresenta a fala de uma imigrante que demonstra essa forma de aprendizagem informal: "agora já posso comer pão de milho! Mas até aprendê-lo, custou trabalho e lágrimas. Agora estou orgulhosa da minha habilidade e já posso impor como professora diante das minhas filhas" (Cartas da esposa de Gustav Stutzer, apud WOLF, 2003, p. 164).

A alimentação é um elemento importante da cultura de qualquer grupo. O ethos próprio da etnia fez com que as mudanças assumissem características específicas. "Os costumes condicionam as formas de adaptação" (SEYFERTH, 2011, p.54). É possível que os colonos, das mais diversas etnias, que migraram para o Brasil tiveram acesso a produtos agropecuários semelhantes, mas cada grupo os adaptou a seu modo. São as características étnicas que definem os hábitos alimentares. Em Santa Catarina, todas as colônias produziam milho; todos criavam porcos, mas o pão de milho e a linguiça fresca de carne suína pura são alemães.

Em muitos lugares do mundo se faz linguiça, mas cada local, cada grupo cultural, 
tem suas especificidades. O hábito de fazer embutidos defumados tem relação com a necessidade de conservação do alimento. Sem refrigeração, a defumação permite que a qualidade da carne se mantenha por mais tempo. Esta necessidade promoveu o desenvolvimento do costume, a tradição que precisava ser ensinada a cada geração.

A linguiça fresca de carne suína pura foi produzida nas casas da antiga colônia Blumenau desde os primeiros anos da instalação dos imigrantes com o objetivo de conservar o alimento. Décadas depois esta situação mudou e as linguiças passaram a ser produzidas também para a comercialização. A formação das colônias ocorreu com o objetivo de ampliar a produção de alimentos e abastecer o mercado interno brasileiro. $\mathrm{Na}$ mesma época que a colônia foi criada, o Brasil passava pela ampliação das lavouras cafeeiras e consequente redução das áreas que produziam os demais gêneros alimentícios. Souto (1999) aponta que na década de 1850 os produtos básicos para alimentação sofreram um aumento de $200 \%$ no mercado brasileiro.

Em função deste contexto, a colônia Blumenau expandiu suas áreas produtivas rapidamente com o objetivo de exportar os produtos coloniais para outras regiões do país. O relatório escrito por Hermann Blumenau em 1862 aponta que anualmente as atividades da colônia estavam se ampliando: mais áreas de cultivo, novos equipamentos para o processamento dos produtos agrícolas como engenhos de cana de açúcar, alambiques, atafonas, padarias e fábricas de cerveja e vinagre (BLUMENAU, 1962).

O crescimento da produção colonial de gêneros alimentícios tem estreita relação com o fenômeno destacado por Souto (1999) entre os anos 1850-1880: a colônia-venda. A maior parte dos colonos produzia gêneros alimentícios, mas ainda assim precisava comprar alguns produtos e bens. Conforme destaca Singer (1968), "o imigrante alemão não se contenta com as possibilidades de consumo que lhe oferece a economia natural; ele provém de uma economia agrária que se mercantiliza”. Em função desta característica cultural, alguns imigrantes assumiram o papel de comerciantes, além de agricultores.

Em cada núcleo colonial, havia um comércio, uma venda, para a qual os colonos levavam seus excedentes de produção e na qual adquiriam os produtos e bens que desejavam. O vendeiro torna-se rapidamente um elemento de importância nos núcleos coloniais porque exerce o monopólio da definição dos preços e do abastecimento daqueles produtos externos como fósforos, querosene, tecidos, louças, sementes. A economia 
desenvolvida no sistema colônia-venda é baseada na troca, trock, no qual o produtor recebe mercadorias ao invés de dinheiro. Pamplona (2007, p. 10) destaca que "o colono que já criava porcos em quantidade além da sua necessidade de carne, passou a usá-los como moeda de troca com o comerciante; esse montava um açougue onde abatia os porcos criados pelo colono". Ostermann relata que já em 1853 “frequentemente [eu] ia a Blumenau vender os produtos de nossa fabricação, como linguiça, manteiga, legumes e frutas" (OSTERMANN, 1862, p.71).

A conveniência deste sistema trouxe prosperidade à região e possibilitou a construção das redes comerciais internas e externas. Stutzer comenta que em 1885:

As casas comerciais contêm em seus estoques mais ou menos o que se consegue comprar na Alemanha em uma região abastada em cidades com 5 a 10 mil habitantes. Comparando-se, portanto, o oferecido por cidades maiores, é possível afirmar que na colônia Blumenau se consegue tudo que é necessário para viver e até alguns artigos de luxo (STUTZER, 1987, p.238).

Durante todo este processo que levou as linguiças produzidas domesticamente a se tornarem produtos de exportação, o aprendizado informal das receitas e técnicas de produção migrou da família para o mundo do trabalho. As vendas ou casas comerciais se tornaram os locais de produção e os espaços para este tipo de aprendizagem. Algumas surgiram e desapareceram ao longo do tempo, enquanto outras prosperaram e se tornaram as raízes do processo de industrialização da região de Blumenau no que se refere à produção de linguiças e demais embutidos. Dentre estes estabelecimentos comerciais peculiares podem-se destacar aqueles pertencentes às famílias Jensen, Schroeder, Hoeschl, Lorenz e Weege.

Nas indústrias os conhecimentos relacionados à produção de linguiça Blumenau foram ensinados e aprendidos ampliando as redes de relacionamento para além dos laços familiares. Surgiu a figura do mestre, detentor das receitas específicas que caracterizavam as linguiças de cada uma das empresas.

Até os dias atuais as receitas continuam sendo ensinadas e aprendidas de geração em geração. Diversos relatos orais permitem mapear a difusão dos conhecimentos e habilidades relacionados a este produto. Andrey Hartmann, bisneto do mestre Willy Piske relata que 
Meu bisavô trabalhou na firma Fritz Lorenz por muitos anos. Foi lá que ele conheceu a receita da linguiça Blumenau. A firma Fritz Lorenz o mandou fazer um curso sobre industrialização e conservação de carnes no frigorífico piloto dos Laboratórios Griffith do Brasil em Mogi das Cruzes. Na época, pessoas de várias regiões iam até lá fazer o curso porque era uma referência nacional.

A receita aprendida e aprimorada por Willy Piske continua sendo ensinada por seus descendentes nos espaços de trabalho. É interessante perceber que a manutenção destas memórias tem relação com os elementos valorizados individualmente e também pelo grupo étnico, como sugerido por Nora (1993).

Dagmar Guenther, filha do mestre Lauro Guenther relata que "meu pai trabalhou muitos anos com Hermann Weege produzindo as linguiças Blumenau da marca Olho, ele sempre gostou de trabalhar com porcos desde criança”. Cinquenta anos depois é o neto Edson Zinnke, sua esposa e filha que dão continuidade à tradição familiar. A relevância dada pelo grupo étnico ao aprendizado das receitas para produção de linguiça Blumenau aparece nas falas dos descendentes através das expressões de afeto porque, conforme destacado por Portelli (1997, p. 38), "as fontes orais envolvem o relato inteiro em sua subjetividade".

Magrit Konell afirma que "alguns funcionários nossos haviam trabalhado na Companhia Jensen e trouxeram a receita da linguiça Blumenau de lá, a partir disso, meu filho desenvolveu e incrementou a receita tornando-a ainda mais especial". Ilze Strube Nagl conta que seu sogro "Franz Nagl, foi consultor contratado pela Companhia Jensen para aprimorar a produção de linguiça Blumenau e nos ensinou a receita da linguiça”.

É interessante apontar o que foi destacado por Seyferth (2011, p.11) no que se refere à industrialização "a relação com os colonos baseou-se na confiança mútua, marcada pelo pertencimento étnico". Este sentimento possibilitou a aprendizagem informal das receitas nos espaços de trabalho, difundindo e aperfeiçoando este conhecimento no interior das redes de relacionamento.

A produção da linguiça Blumenau é um saber-fazer tradicional da região de Blumenau. As receitas da linguiça fresca trazidas pelos imigrantes alemães foram desenvolvidas pelos comerciantes em seus açougues. Estes deram origem às indústrias tradicionais que através da pesquisa e da adequação sanitária exigida pela legislação incrementaram as receitas tradicionais. Usando as receitas industriais criadas entre os anos 
1930 e 1970, novas empresas especializadas em embutidos e defumados assumiram o protagonismo. Receitas herdadas e tradições familiares definem a produção da linguiça Blumenau nos dias atuais. Pelegrini (2007, p.91) destaca que "A atribuição de valores e simbologias a determinados bens materiais ou imateriais adquire, no decorrer do tempo histórico, sentidos e vivências subjetivas, determinadas pela relação que esses objetos estabelecem com os sujeitos ou grupos sociais."

\section{CONSIDERAÇÕES FINAIS}

Santa Catarina é um Estado brasileiro cuja história contemporânea foi fortemente marcada pela chegada dos imigrantes. Desde o século XVIII com a chegada dos primeiros casais açorianos, depois, durante o século XIX, com a implantação das diferentes colônias na planície costeira, até o século XX com a chegada de novos grupos na região do planalto, o fenômeno migratório é fator constituinte de sua história e do modo de ser da sua população.

A presença dos imigrantes provocou efeitos. Viver em outra sociedade implica em construir adaptações tanto do ponto de vista econômico quanto da cultura. Considerando que trabalho e cultura possuem estreita relação, as adaptações para produção de alimentos e dos bens de consumo necessários, consequentemente, causam impactos culturais tanto nos imigrantes quanto naqueles que com os quais mantiveram contato. Imigrar promove continuidades, rupturas e desdobramentos.

Logo, qualquer aspecto da história de Santa Catarina sofreu influências deste fenômeno. A presença de tais influências é visível em vários campos, como religião, política, economia, alimentação e, com destaque, educação. Refletir sobre a educação implica pensar nos imigrantes e suas estratégias tanto de escolarização quanto de manutenção de elementos culturais através das gerações, bem como, do trabalho empregando estratégias educativas informais.

Pensando a educação como a ação da sociedade sobre as gerações jovens com o objetivo de conservar e transmitir seus valores e estratégias coletivas pode-se considerar que cada grupo constrói práticas educativas informais específicas relacionadas com sua realidade, enfatizando os elementos considerados importantes do ponto de vista cultural, 
econômico e político. O isolamento dos núcleos coloniais se refletiu nas formas que as adaptações culturais assumiram na região. O ambiente natural e econômico do Vale do Itajaí no século XIX promoveu mudanças nos padrões de alimentação, moradia, vestuário, nas atividades econômicas e em outros aspectos do modo de vida dos colonos.

A educação informal se estende por todas as esferas da sociedade, tais como a família e o ambiente de trabalho. Em outras palavras, a educação está inserida na sociedade e conforme o grupo se adapta e se reinventa, se organizam os processos de ensino e aprendizagem. A história da aprendizagem informal para a produção da linguiça Blumenau reflete a complexidade dos processos de imigração que ocorreram em Santa Catarina e caracterizaram a sociedade catarinense. Os produtos agroalimentares considerados típicos se constituíram a partir de um duplo estímulo: de um lado econômico e de outro cultural. É relevante considerar que os produtos alimentares, como a linguiça Blumenau, são limitados pela existência de matérias-primas e condições ambientais para que sejam produzidos. De outro lado, a escolha por um produto, em detrimento de muitas outras possibilidades, tem estreita relação com o ethos cultural, ou seja, com o conjunto de costumes e hábitos compartilhados pelo grupo social, neste caso os imigrantes alemães.

Assim, os saberes do grupo associados ao território em que se encontravam levaram ao desenvolvimento da linguiça Blumenau. Este produto tornou-se tão importante do ponto de vista cultural que o ensino e aprendizagem informais das receitas perdurou nas famílias e, conforme ocorreu o desenvolvimento econômico local, migrou para o mundo do trabalho. Como destacado por Jost Weege, em entrevista à Olho Embutidos e Defumados, "nem na Alemanha se fabrica esta linguiça, veio uma receita base de lá, que foi modificada aqui para os nossos termos e o nosso clima muito favorável para a linguiça Blumenau".

Pensar sobre a História da Educação nas colônias teuto-brasileiras envolve a compreensão das teias de relações sociais e econômicas que se desenvolveram nestes grupos. Na sua trajetória histórica, as colônias promoveram processos educativos variados envolvendo os espaços formais, informais, envolvendo a escola, a família e o mundo do trabalho e contribuíram com a complexidade e diversidade da educação catarinense e brasileira. Conhecer a complexidade que integra a educação formal e informal é fundamental ao profissional da educação para pensar tanto o fazer pedagógico quanto seu 
papel na sociedade.

\section{REFERÊNCIAS}

ANNUÁRIO DO ENSINO DO ESTADO DE SÃO PAULO. São Paulo: Directoria Geral de Instrucção Pública, 1918.

ARON, Jean-Paul. A cozinha: um cardápio do século XIX. In: LE GOFF, Jacques; NORA, Pierre (Eds.). História: novos objetos. Rio de Janeiro: Francisco Alves, 1974. p. 160-185.

BACELLAR, Carlos. Uso e mau uso dos arquivos. In: PINSKY, Carla Bassanezi (org). Fontes Históricas. São Paulo: Contexto, 2015. p.23-79.

BLUMENAU, H. Notas Estatísticas sobre a Colônia Blumenau (Província de Santa Catarina) no Sul do Brasil do ano de 1862. Blumenau em Cadernos, v.5, n.4, p.1-24, 1962.

BOM MEIHY, José Carlos. Manual de História Oral. São Paulo: Loyola, 2004.

CASCUDO, Luís da Câmara. História da Alimentação no Brasil: pesquisas e notas. São Paulo: Edusp, 1983.

DALL'ALBA, João Leonir. Santa Catarina: estado de graça. Orleans: Gráfica do Lelo, 2008.

DE MARTINI, Zeila de Brito Fabri. Imigrantes: entre políticas, conflitos e preconceitos.

Cadernos Ceru, v. 21, n.2, p. 49-75, dez. 2010.

FERREIRA, Marieta de Moraes. Notas iniciais sobre a história do tempo presente e a historiografia no Brasil. Tempo e Argumento, Florianópolis, v. 10, n. 23, p.80-108, 2018.

GERLACH, Gilberto Schmidt (org.). Colônia Blumenau no sul do Brasil. São José: Clube de Cinema Nossa Senhora do Desterro, 2019.

IBGE - Instituto Brasileiro de Geografia e Estatística. Cidades. Disponível em https://cidades.ibge.gov.br/. Acessado em 10 out 2020.

KLUG, João. A Escola Teuto-Catarinense e o Processo de Modernização em Santa Catarina: ação da igreja luterana através das escolas (1871-1938). 1997. 213p. Tese (Doutorado em História Social). Universidade de São Paulo/ USP, São Paulo, 1997.

$\mathrm{KOCH}$, Walter. A escola evangélica teuto-brasileira. In: FIORI, Neide Almeida (org.) Etnia e Educação: a escola "alemã” do Brasil e estudos congêneres. Florianópolis: Editora da UFSC, 2003. P. 77-92.

LUNA, José Marcelo Freitas de. $O$ português na escola alemã de Blumenau: da formação à extinção de uma prática. Blumenau: Editora da FURB, 2000. 178p. 
MENESES, Ulpiano T. Bezerra; CARNEIRO, Henrique. A História da Alimentação: balizas historiográficas. Anais do Museu Paulista, São Paulo, v.5, p. 9-91, 1997.

NORA, Pierre. Entre memória e história: a problemática dos lugares. Projeto História, São Paulo, n. 10, p. 7-28, jul - dez 1993.

OSTERMANN, Ferdinand. A História de Blumenau na Correspondência dos Imigrantes. Blumenau em Cadernos., v.9, n.4, p.71, Nov 1862.

PAMPLONA, Nelson Vieira. Sabores da Colônia Blumenau: a história dos que produziam defumados e queijos; Edição do Autor, 2007.

PELEGRINI, Sandra C.A. A gestão do patrimônio imaterial brasileiro na contemporaneidade. História, São Paulo, v.27, n. 2, p. 145-173.

PELEGRINI, Sandra C.A. O patrimônio cultural e a materialização das memórias individuais e coletivas. Patrimônio e Memória, v. 3, n. 1, p. 87-100, 2007.

PIAZZA, Walter Fernando; HUBENER, Laura Machado. Santa Catarina: história da gente. Florianópolis: Editora Lunardelli, 2003.

PORTELLI, Alessandro. História oral como arte da escuta. São Paulo: Letra e voz, 2016.

PORTELLI, Alessandro. O que faz a história oral diferente. Proj. História, São Paulo, v. 14, p. 25-39, 1997.

RELATÓRIO sobre as escolas dos tiroleses na paróquia de Rodeio - Município de Blumenau em 1910. Blumenau em Cadernos, n. 2, p. 53-54, fev. 1987.

RICOEUR, Paul. A memória, a história, o esquecimento. Campinas/SP: Editora da Unicamp, 2007.

SANTOS, Ademir Valdir dos. Zeitgeist ou espírito alemão: etno-história de germanidade e instituição da escola em Santa Catarina. Educação e Pesquisa, São Paulo, v. 41, n. 2, p. 325340, jun. 2015.

SEYFERTH, Giralda. Socialização e Etnicidade: a questão escolar teuto-brasileira (18501937). Mana, Rio de Janeiro, v. 23, n. 3, p. 579-607, set. 2017.

SEYFERTH, Giralda. A dimensão cultural da imigração. Revista Brasileira de Ciências Sociais, v. 26, n. 77, p. 47-62, 2011.

SEYFERTH, Giralda. A conflituosa história da formação da etnicidade teuto-brasileira. In: FIORI, Neide Almeida (org.) Etnia e Educação: a escola "alemã" do Brasil e estudos congêneres. Florianópolis: Editora da UFSC, 2003. P. 77-92. 
Revista do Programa de Pós-Graduação em Educação da Unochapecó ISSN 1984-1566 (on-line) ISSN 1415-8175 (impressa)

SEYFERTH, Giralda. Imigração e cultura no Brasil. Brasília: UnB, 1990

SILVA, Maurício R.; COSTA, Miguel Angelo S. da. Educação não-formal e informal: outros textos e contextos educacionais. Revista Pedagógica, v. 15, n.31, p. 5-15, jul-dez, 2013.

SILVA, Daniele Hungaro da; MONTAGNOLI, Gilmar Alves. Uma perspectiva formal e informal em pauta: a relação educação e trabalho. Revista Pedagógica, v. 15, n. 31, p. 5971, jul-dez 2013.

SINGER, Paul. Desenvolvimento econômico e evolução urbana. São Paulo: Editora da USP, 1968.

SOUTO, Américo Augusto da Costa. Industrialização de Santa Catarina: o Vale do Itajaí e o litoral de São Francisco, das origens ao mercado nacional (1850-1929). In: BRANCHER, Ana (org.). História de Santa Catarina: estudos contemporâneos. Florianópolis: Letras Contemporâneas, 1999.

STUTZER, Gustav. O Vale do Itajaí e o Município de Blumenau (1885). Blumenau em Cadernos, v 28, n.8, p. 238-246, fev 1987.

WIEDERKHER, Alessandra Helena. A gênese da escola alemã no sul do Brasil. Florianópolis: Insular, 2014.

WOLFF, Cristina Scheibe. Como se forma uma "boa dona de casa": a educação das mulheres teuto-brasileiras na Colônia Blumenau (1850-1900). In: MORGA, Antonio. A História das Mulheres de Santa Catarina. Florianópolis: Letras Contemporâneas, 2003. p. 158-180.

Fontes orais

GUENTHER, Dagmar. Entrevista concedida a Paola Beatriz May Rebollar em 25 de setembro de 2020 na sede da Frigozinnke em Pomerode, Santa Catarina.

HARTMANN, Andrey. Entrevista concedida a Paola Beatriz May Rebollar em 25 de setembro de 2020 na sede da Fricar Alimentos, Timbó, Santa Catarina.

KONELL, Magrit. Entrevista concedida a Paola Beatriz May Rebollar em 25 de setembro de 2020 na sede da Konell Alimentícios em Blumenau, Santa Catarina.

NAGL, IlzeStrube; ZINNKE, Edson. Entrevista concedida a Paola Beatriz May Rebollar em 25 de setembro de 2020 na sede da Deschamps Alimentos em Gaspar, Santa Catarina.

Recebido em: 21 - 05 - 2021

Aprovado em: 25 - 06 - 2021

Publicado em: 29-06-2021 